\title{
Verification of the internal tide off Zhiben coast, Taitung, southeast Taiwan
}

\author{
Yiing-Jang Yang ${ }^{1}$, Chan-Chuan Wen ${ }^{2}$, Ping-Yi Huang ${ }^{3}$, Cheng-Yun Wang ${ }^{1}$, Ken-Sheng Chu ${ }^{1}$, and \\ Su-Cheng Pai ${ }^{1, *}$ \\ ${ }^{1}$ Institute of Oceanography, National Taiwan University, Taipei City, Taiwan \\ ${ }^{2}$ Department of Shipping Technology, National Kaohsiung University of Science and Technology, Kaohsiung City, Taiwan \\ ${ }^{3}$ Water Resources Division, Stone \& Resource Industry R\&D Center, Hualien County, Taiwan
}

\section{Article history:}

Received 28 March 2019

Revised 13 July 2019

Accepted 14 July 2019

Keywords:

Nutrients, Pipeline, Internal tide, Taitung

Citation:

Yang, Y.-J., C.-C. Wen, P.-Y. Huang, C.-Y. Wang, K.-S. Chu, and S.-C. Pai, 2020: Verification of the internal tide off Zhiben coast, Taitung, southeast Taiwan. Terr. Atmos. Ocean. Sci., 31, 77-83, doi: 10.3319/

TAO.2019.07.14.01

\begin{abstract}
An oscillating vertical movement of the undersurface water layers has been verified off the coast of Zhiban, Taitung, southeast Taiwan. It was first suspected to exist by significant variations of CTD temperature profiles observed on Cruises OR3-1769 and OR3-1792 in 2014. A frequency of $12.5 \mathrm{hr}^{-1}$ was estimated from temperature record by a subsurface ADPC moored at a depth of $110 \mathrm{~m}$. Further proofs were obtained in 2016 by chemical measurements of silicate and phosphate in an industrial pipeline which takes up continuously the deep ocean water at a depth of $319 \mathrm{~m}$. The nutrient concentrations varies hour by hour during a $36-\mathrm{hr}$ period $(0.88-1.11 \mu \mathrm{M}$ for phosphate and $19.0-26.2 \mu \mathrm{M}$ for silicate), showing a semi-diurnal cycle which matched well with that of the surface tide reported at a near-by tidal station. An amplitude of $60-100 \mathrm{~m}$ that occurs in a semidiurnal cycle can be commonly observed in this area at depths between 100 and $300 \mathrm{~m}$.
\end{abstract}

\section{INTRODUCTION}

The topography off the coast of eastern Taiwan is quite unique in terms of steepness comparing to other parts of the island. The shelf facing the Pacific Ocean side is narrow and the seafloor can drop sharply to more than $1000 \mathrm{~m}$ deep only a few $\mathrm{km}$ away from the shore line. Due to this reason the eastern Taiwan becomes a potential area for developing deep ocean water industry. Hualien is the first place to choose where five pipelines have already been implemented for obtaining cold/clean deep ocean water (depths between 400 and $718 \mathrm{~m}$ ) for manufacturing drink water and mariculture (Takahashi et al. 2012; Pai et al. 2015). Taitung coast is another potential area but several prior attempts of deploying pipelines have not been successful due to blockage or breaking by unidentified forces. The reason could be related to the frequent geological activities (earthquake, density flow or subsurface landslide), or the water body itself may not be stable (current, typhoon or internal tide). Although the

\footnotetext{
* Corresponding author

E-mail: scpai@ntu.edu.tw
}

exact reason has not been identified, it is suspected that the internal tidal movement can affect the buoyance of water, especially in the pycnocline layer, and the velocity shearing force may distort the layout of the pipeline which was lying above the sea floor without protection. The internal tidal waves, which have been observed recently in adjacent areas [in Hualien area by Lien et al. (2014), Pai et al. (2017); and in Luzon Strait by Jan et al. (2007), Alford et al. (2011, 2015)], has not been reported in Taitung area. Its amplitude and frequency need to be identified quantitatively.

\section{METHODOLOGY}

\subsection{CTD Profiles and ADCP Record}

Selected offshore hydrographic data were obtained during two physical oceanography cruises, namely the Cruise OR3-1769 (28 to 31 May 2014) and Cruise OR3-1792 (30 August to 2 September 2014). Both cruises have nine CTD stations outside the river mouth of the Zhiben Creek (Fig. 1). On the later cruise, a mooring with a subsurface ADCP was 
deployed at a location ca. $1 \mathrm{~km}$ off the coast. Its temperature sensor was bound at a depth of $110 \mathrm{~m}$ and the bottom depth was $210 \mathrm{~m}$. A total period of $54 \mathrm{hr}$ was monitored.

\subsection{Pipeline}

A pipeline was deployed in 2015 as a pioneer project by the Ministry of Economics, Taiwan (Fig. 2, drawn according to information provided by P.-Y. Huang) with an underwater length of $2100 \mathrm{~m}$ plus a $300 \mathrm{~m}$ distance from the water line to the pumping station. The pumping station is located at $121^{\circ} 3^{\prime} 26.0^{\prime \prime} \mathrm{E}, 22^{\circ} 40^{\prime} 59.4^{\prime \prime} \mathrm{N}$, at the southern bank of the river mouth of Zhiben Creek. The average dipping angle on the ocean floor was $8.37^{\circ}$. The intake depth was reported at $319 \mathrm{~m}$. Like all other pipelines, the intake point at the end did not lie directly on the seafloor but was mounted to a metal frame to lift the hose head a few meters above the sea floor. The pipe was made of PVC material with an outer diameter of $160 \mathrm{~mm}$ and an internal diameter of $130.8 \mathrm{~mm}$. Accordingly, the total volume of the pipeline was estimated to be $32 \mathrm{~m}^{3}$. Since the pipeline was operated regularly at a rate of 70 ton per day, the residence time for water to travel in the pipeline was circa $11 \mathrm{hr}$. It means that the water obtained at the pumping station has an $11 \mathrm{hr}$ lag from the intake point. The pumping operation is normally stopped during Typhoon, earthquake or whenever the turbidity turns high. However, the traveling time in the pipeline is long, the turbidity check could be late if any unexpected underwater landslide occurs. In fact, the pipeline studied in this work was blocked few months after the sampling.

\subsection{Sampling and Chemical Measurement}

Seawater was collected hourly at the Zhiben Pumping Station from 8:00 AM 24 May 2016 to 20:00 PM next day. A total of 36 bottles were obtained. They were put in black plastic bags to shade from the light, dispatched promptly to the laboratory in Taipei for nutrient analyses. Phosphate and silicate concentrations were measured simultaneously in a way as described previously (Pai et al. 2017).
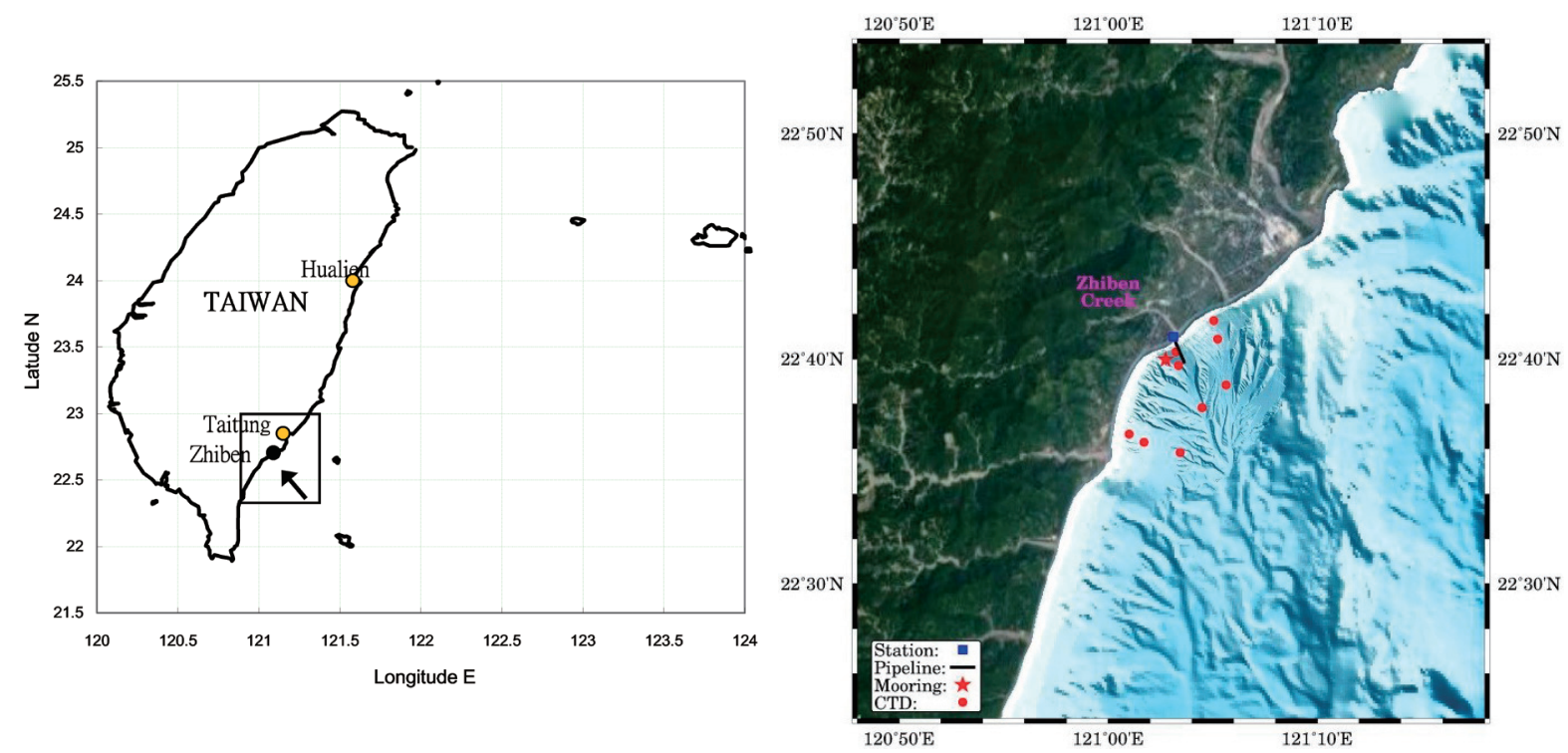

Fig. 1. (Left) The studied area off the coast of Taitung and Zhiben. (Right) Locations of CTD stations of Cruises OR3-1769 and OR3-1792 are marked by dots, and the mooring site of the subsurface ADCP is marked by a star. The pipeline pumping station at the south bank of the Zhiben Creek is marked by a square. A pipeline stretches out from coast toward the sea in SSE direction.

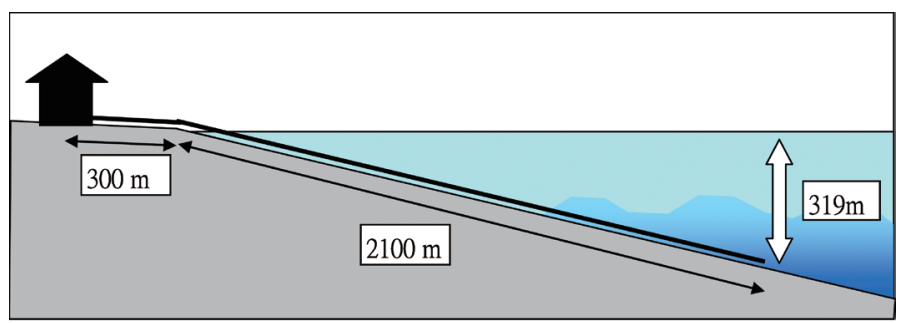

Fig. 2. An illustrative diagram showing the Zhiben Creek pipeline which stretches from the pumping station toward the ocean. The average dipping angle on the seafloor is $8.37^{\circ}$. The end of the pipeline is $121^{\circ} 4^{\prime} 27.6^{\prime \prime} \mathrm{E}, 22^{\circ} 39^{\prime} 53.5^{\prime \prime} \mathrm{N}$, with an intake depth of $319 \mathrm{~m}$. 


\section{RESULTS}

\subsection{Temperature Profile}

Vertical temperature profile data were obtained by CTD during cruises OR3-1769 and OR3-1792 (the operation in each cruise covered a time span of ca. $24 \mathrm{hrs}$ ). There were nine stations for each cruise. The composite profiles (see Fig. 3) show scattered patterns beneath the surface layer. At $100 \mathrm{~m}$, temperature ranged from $17-24$ and $17.2-20^{\circ} \mathrm{C}$ for the two cruises, respectively. At $300 \mathrm{~m}$ depth, the ranges were $12.0-13.6$ and $11.1-13.9^{\circ} \mathrm{C}$, respectively. Since all CTD casts were not designated to operate in consistent time intervals, the large temperature variations (up to $7^{\circ} \mathrm{C}$ at $100 \mathrm{~m}$ and up to $1.8^{\circ} \mathrm{C}$ at $300 \mathrm{~m}$ ) observed can hardly be used directly to quantify the water mass movement. However, the TS diagrams (also in Fig. 3) show that all curves are likely merged with each other, indicating the movement of water mass is in a typical vertical up-and-down direction rather than any lateral intrusion from other water masses.

Nonetheless, a rough estimation could still be made by treating those differences as a relevant measure of the $95 \%$ confidence level and dividing them by empirical temperature gradients (e.g., $0.05^{\circ} \mathrm{C} \mathrm{m}^{-1}$ at $100 \mathrm{~m}$ and $0.025^{\circ} \mathrm{C} \mathrm{m}^{-1}$ at $300 \mathrm{~m}$ ). In this way the possible vertical displacements $[\Delta z \fallingdotseq 4 \sigma /(d T / d z)]$ at depths of 100 and $300 \mathrm{~m}$ would be as large as 140 and $64 \mathrm{~m}$ for Cruise OR3-1769, whereas 56 and $110 \mathrm{~m}$ for Cruise OR3-1792, respectively.

\subsection{ADCP Record}

A sub-surface ADCP unit with a temperature sensor tied at $110 \mathrm{~m}$ at station CP1 during 30 August to 1 September 2014 for $54 \mathrm{hr}$. The temperature variations at $110 \mathrm{~m}$ as well as current speeds at $100 \mathrm{~m}$ are shown in Fig. 4. It is clear that all data show four and a half cycles, matching the surface semi-diurnal tidal frequency. The lowest temperature was $17^{\circ} \mathrm{C}$ and the highest $22^{\circ} \mathrm{C}$ with a range difference of $5^{\circ} \mathrm{C}$. Following the estimation method in the above section, the vertical variation of the water layer at $100 \mathrm{~m}$ depth could be as large as $100 \mathrm{~m}$.

\subsection{Variation on Nutrients in Pipeline}

The measurement of chemical compositions in pipeline water may provide another approach to estimate the vertical movement. The results of analyses for phosphate and silicate in the pipeline water are given in Table 1 . In the $36 \mathrm{hr}$ observation period, the phosphate concentration changed up-and-down three times, from as low as 0.88 to a highest $1.11 \mu \mathrm{M}$, with an average of $1.0 \pm 0.06 \mu \mathrm{M}$. If a $4 \sigma$ range is taken account for the daily variation, the relative range ( $95 \%$ confidence level) was about $24 \%$ of the mean value. As to silicate, the concentration also changed up-and-down three times, between 21.8 and $25.4 \mu \mathrm{M}$. with a mean value of
$22.96 \pm 1.65 \mu \mathrm{M}$. The relative daily variation is about $28 \%$ of the mean value. The $[\mathrm{Si}] /[\mathrm{P}]$ molar ratio was $22.9 \pm 0.9$, indicating that both nutrients were changing in a synchronized way, and the frequency was approximately $12 \mathrm{hr}^{-1}$.

\section{DISCUSSION}

\subsection{Correlation Analysis}

In order to identify the relationship between nutrient variation and surface tidal cycle, an autocorrelation process was made on the data of Table 1. For a set data containing $N$ pair numbers $\left(X_{1}, Y_{1}, \ldots X_{\mathrm{N}}, Y_{\mathrm{N}}\right)$. The autocorrelation factor $A C F(k)$ at a given lag number $k$, is defined as:

$A C F(k)=\frac{\sum_{i=1}^{N-k}\left(Y_{i}-\bar{Y}\right)\left(Y_{i+k}-\bar{Y}\right)}{\sum_{i=1}^{N}\left(Y_{i}-\bar{Y}\right)^{2}}$

where $\bar{Y}$ is the mean value.

Surface tidal heights (at Fugang Tidal Station, Central Weather Bureau, Taiwan), phosphate and silicate data sets were analyzed and the $A C F$ diagrams (Fig. 5) all show a typical semidiurnal pattern with an average period of circa $12.5 \mathrm{hr}$. However, the nutrient peaks appeared some $3-4 \mathrm{hr}$ behind that of the surface tide. It should also be borne in mind that the water needs an $11 \mathrm{hr}$ period to reach at the station. With this consideration, the deep internal tide is either leading the nutrient patterns by circa $5 \mathrm{hr}$ or adrift by $7.5 \mathrm{hr}$.

Several recent studies in adjacent areas have revealed that the phase lags between deep and surface tides may differ from place to place. The phases of the $170 \mathrm{~m}$ internal tide and the surface tide were almost opposite (-6 hr) in the Hungtsai Trough, southern Taiwan (Pai et al. 2016). The surface tide was ca. $+2 \mathrm{hr}$ earlier than that of the internal tide at $400 \mathrm{~m}$ off Hualien coast (Pai et al. 2017). The phase difference may be difficult to explain as it could be affected by many geographic factors such as local topography, direction/reflection of wave propagation and the distance travelled from the generation area.

\subsection{Vertical Displacement by Nutrient Variation}

It is possible to estimate the scale of the vertical displacement $(\Delta z)$ by taking quadruple standard deviation (95\% confidence level) of nutrient concentration and divided it by the average profile gradient at the same depth:

$\Delta z(\mathrm{~m}) \fallingdotseq 4 \sigma /(d[C] / d z)$

By referring to historic data, the nutrient vertical gradient values $d C / d z$ at $300 \mathrm{~m}$ can be estimated graphically as $0.004 \mu \mathrm{M} \mathrm{m}^{-1}$ for phosphate and $0.1 \mu \mathrm{M} \mathrm{m}^{-1}$ for silicate. In 
Cruise OR3-1769 2014/5/29
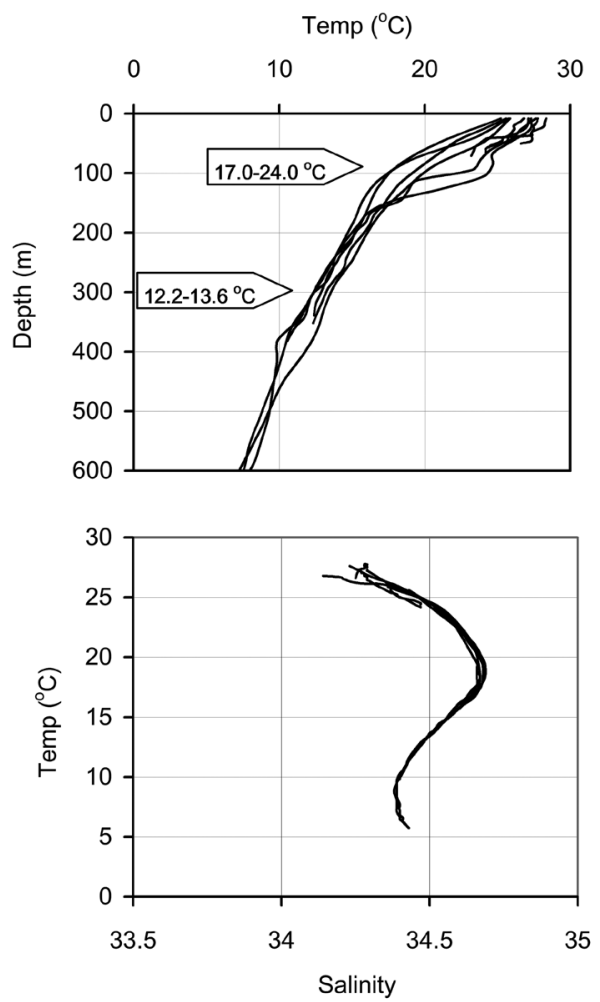

Cruise OR3-1792 2014/8/30
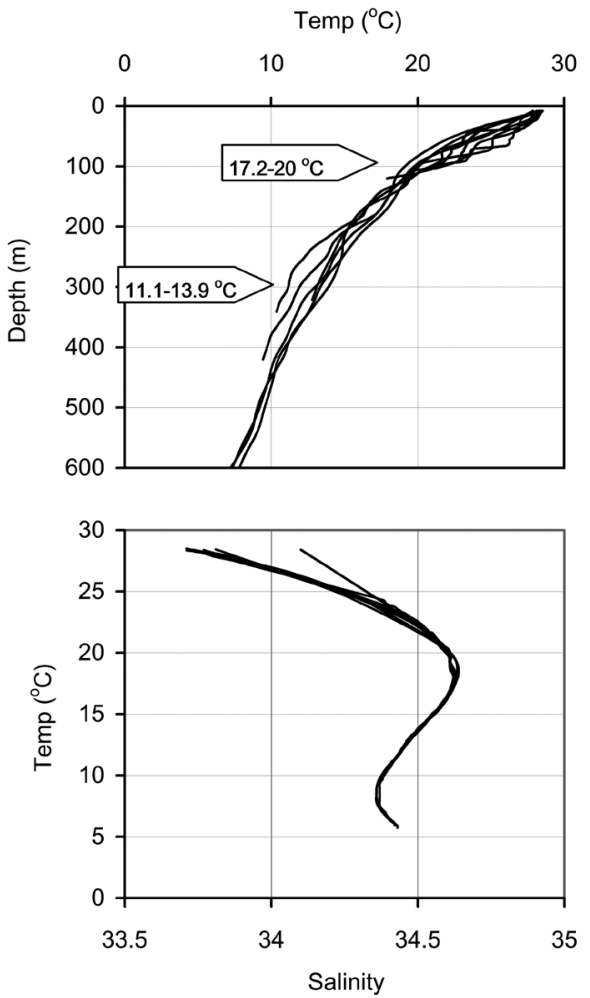

Fig. 3. (Up) Composite CTD temperature profiles for Cruises OR3-1769 and OR3-1792. The variation ranges for temperature at 100 and $300 \mathrm{~m}$ were 7 and $1.4^{\circ} \mathrm{C}$ for OR3-1769, whereas 2.3 and $2.8^{\circ} \mathrm{C}$ for OR3-1792. (Down) Merged lines in TS diagrams showing the variations were induced by a simple vertical movement.
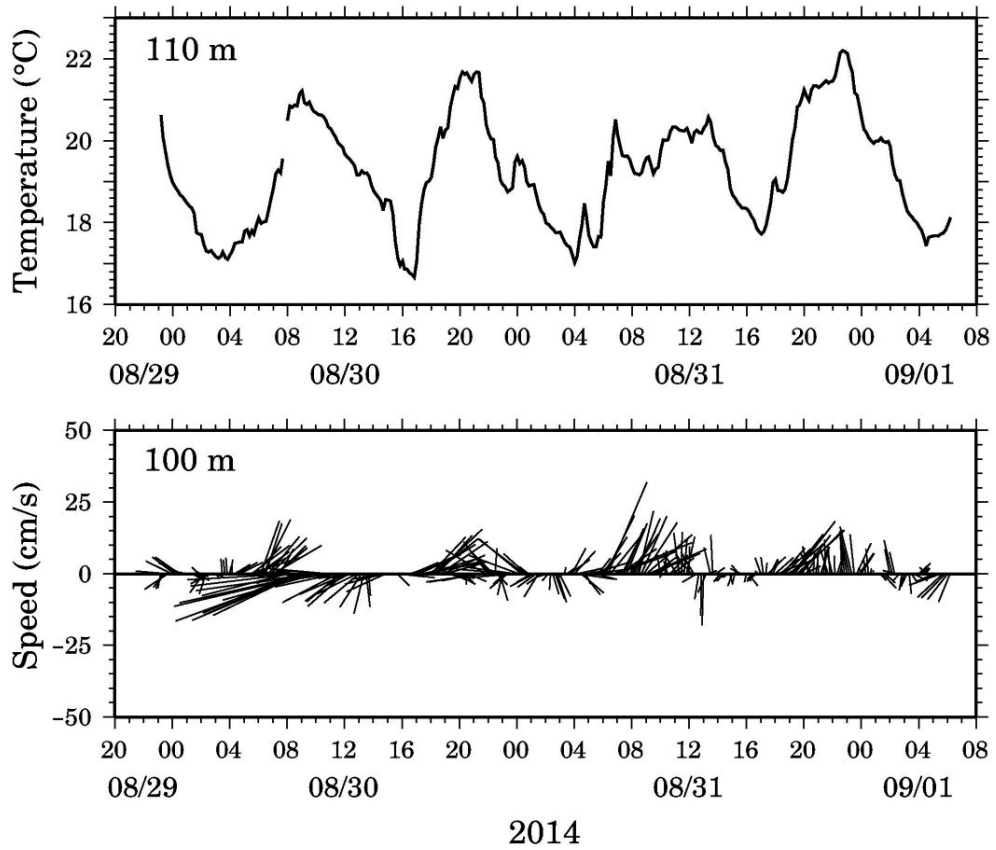

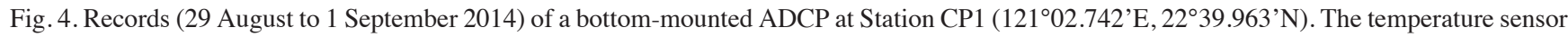
was bound at $110 \mathrm{~m}$ and the water depth was $210 \mathrm{~m}$. The current speed and direction at $100 \mathrm{~m}$ level were presented in the lower diagram. All data show typical semi-diurnal tidal cycles. 
Table 1. Hourly variations of nutrients in seawater from the Zhiben $319 \mathrm{~m}$ pipeline.

\begin{tabular}{|c|c|c|c|c|c|}
\hline Sampling date & Time (hh:mm) & Tidal ht (m) & {$[\mathrm{PO4}](\mu \mathrm{M})$} & [Silicate] $(\boldsymbol{\mu M})$ & {$[\mathrm{Si}] /[\mathrm{P}]$ ratio } \\
\hline \multirow[t]{16}{*}{$2016 / 5 / 24$} & 08:00 & 0.86 & 1.06 & 22.55 & 21.3 \\
\hline & 09:00 & 0.65 & 1.06 & 24.88 & 23.5 \\
\hline & $10: 00$ & 0.35 & 1.11 & 24.35 & 22.0 \\
\hline & 11:00 & 0.02 & 1.06 & 24.42 & 23.1 \\
\hline & $12: 00$ & -0.29 & 1.06 & 23.56 & 22.3 \\
\hline & $13: 00$ & -0.48 & 1.01 & 25.15 & 24.9 \\
\hline & $14: 00$ & -0.54 & 1.01 & 23.64 & 23.4 \\
\hline & $15: 00$ & -0.47 & 0.96 & 21.79 & 22.7 \\
\hline & $16: 00$ & -0.22 & 0.96 & 21.84 & 22.7 \\
\hline & $17: 00$ & 0.03 & 0.91 & 22.42 & 24.5 \\
\hline & 18:00 & 0.29 & 0.96 & 21.44 & 22.3 \\
\hline & 19:00 & 0.51 & 0.96 & 21.39 & 22.2 \\
\hline & 20:00 & 0.6 & 0.96 & 21.34 & 22.2 \\
\hline & 21:00 & 0.6 & 1.01 & 22.58 & 22.4 \\
\hline & $22: 00$ & 0.48 & 1.06 & 23.66 & 22.4 \\
\hline & 23:00 & 0.32 & 1.11 & 26.16 & 23.7 \\
\hline \multirow[t]{21}{*}{$2016 / 5 / 25$} & 00:00 & 0.11 & 1.11 & 25.86 & 23.4 \\
\hline & 01:00 & -0.04 & 1.06 & 25.89 & 24.5 \\
\hline & 02:00 & -0.05 & 1.06 & 23.31 & 22.0 \\
\hline & 03:00 & 0.09 & 1.01 & 22.42 & 22.2 \\
\hline & 04:00 & 0.28 & 0.88 & 19.01 & 21.7 \\
\hline & 05:00 & 0.54 & 0.96 & 20.28 & 21.1 \\
\hline & 06:00 & 0.76 & 0.89 & 20.01 & 22.5 \\
\hline & 07:00 & 0.9 & 0.96 & 21.39 & 22.2 \\
\hline & 08:00 & 0.9 & 0.96 & 22.04 & 22.9 \\
\hline & 09:00 & 0.76 & 1.01 & 22.78 & 22.6 \\
\hline & $10: 00$ & 0.51 & 1.01 & 23.74 & 23.5 \\
\hline & 11:00 & 0.19 & 1.06 & 24.88 & 23.5 \\
\hline & $12: 00$ & -0.13 & 1.06 & 24.67 & 23.3 \\
\hline & 13:00 & -0.39 & 1.01 & 23.54 & 23.3 \\
\hline & $14: 00$ & -0.52 & 1.01 & 23.74 & 23.5 \\
\hline & $15: 00$ & -0.55 & 0.96 & 22.45 & 23.3 \\
\hline & $16: 00$ & -0.4 & 0.97 & 22.45 & 23.2 \\
\hline & $17: 00$ & -0.17 & 0.91 & 22.22 & 24.3 \\
\hline & 18:00 & 0.1 & 0.96 & 21.89 & 22.8 \\
\hline & 19:00 & 0.34 & 0.96 & 22.60 & 23.5 \\
\hline & \multirow[t]{6}{*}{ 20:00 } & 0.5 & 1.01 & 23.33 & 23.1 \\
\hline & & Mean & 1.00 & 22.96 & 22.92 \\
\hline & & $\sigma$ & 0.06 & 1.65 & 0.87 \\
\hline & & $4 \sigma$ & 0.24 & 6.59 & \\
\hline & & $d C / d z$ & 0.004 & 0.1 & \\
\hline & & $\Delta z$ & 60 & 66 & \\
\hline
\end{tabular}

Note: Tidal height data were obtained from Fugong Tidal Station, Taitung. 

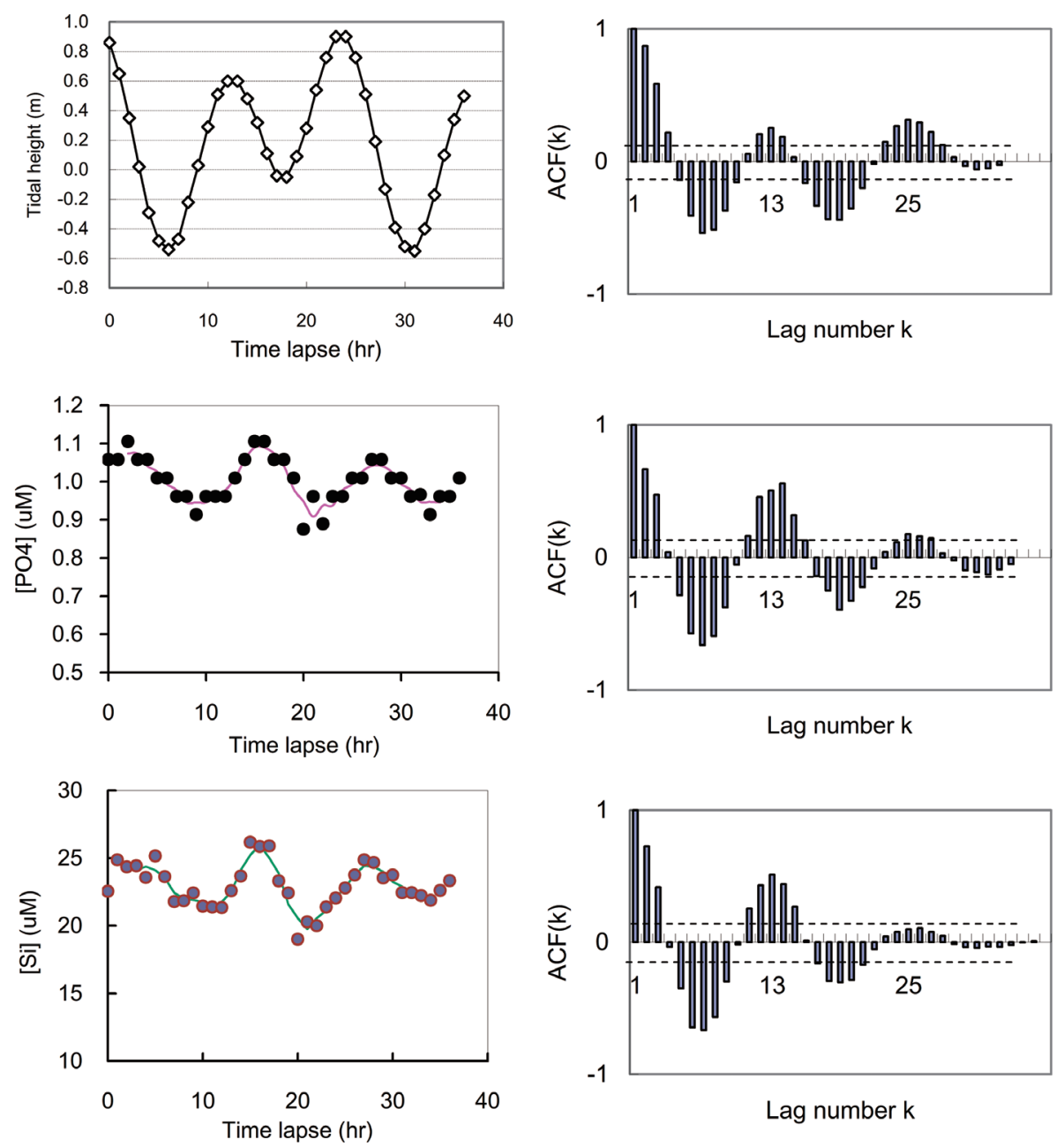

Fig. 5. Temporal variation of (top) surface tidal height at Fugang Harbor, Taitung (source: Central Weather Bureau, Taiwan), (middle) phosphate and (bottom) silicate concentrations in the pipeline during the $36 \mathrm{hr}$ period starting at 8:00 24 May 2016. The corresponding correlograms are shown on the right indicating typical semidiurnal cycles of ca. $12.5 \mathrm{hr}$. Dashed lines remark the $95 \%$ confidence intervals.

this case it is readily to obtain $\Delta z=60 \mathrm{~m}$ by phosphate data and $\Delta z=66 \mathrm{~m}$ by silicate data (see Table 1 ). These values are comparable to that estimated by CTD temperature data. It is also similar in scale to that reported in Hualien area (nearly $90 \mathrm{~m}$ at $300 \mathrm{~m}$, Pai et al. 2017).

\subsection{Verdict by Temperature Variation}

An empirical relationships between temperature $\left({ }^{\circ} \mathrm{C}\right)$ and silicate concentration $(\mu \mathrm{M})$ have been proposed for the off shore water column in the eastern Taiwan area (Pai et al. 2017):

$T\left({ }^{\circ} \mathrm{C}\right)=1 /\left\{0.04-\frac{1}{10.5} \ln \left[1-\left(\frac{[\mathrm{Si}]-1}{147}\right)^{0.588}\right]\right\}$

By putting the silicate data in Table 1 into the above equation, the temperature range at the $319 \mathrm{~m}$ depth intake point was be estimated to be $12.3-13.8^{\circ} \mathrm{C}$ with a difference of $1.5^{\circ} \mathrm{C}$. At $300 \mathrm{~m}$, by taking account of a gradient value of $d T / d z=0.025^{\circ} \mathrm{C} \mathrm{m}^{-1}$, the $1.5^{\circ} \mathrm{C}$ variation may be regarded as a vertical displacement of $60 \mathrm{~m}$ on that day.

\section{CONCLUSION}

Only two decades ago most people would think that the deep ocean off Taiwan should be very stagnant, therefore it is reasonable to expect obtaining temperature-consistent clean/cold seawater from several hundred meters below the surface. Nowadays scientists have found that internal tides can affect significantly the intermediate layers. In this work, we have confirmed that in Taitung area, there indeed exists a consistent vertical movement of water layers in the thermocline. The variations, frequencies and displacements were first estimated by CTD measurements on two cruises and records from a subsurface mooring ADCP. Those physical judgements were consolidated by chemical measurements 
in water collected from a local industrial pipeline with an intake depth of $319 \mathrm{~m}$. The nutrient concentration variations in a $36 \mathrm{hr}$ period (for both phosphate and silicate) were as large as $24-28 \%$, which reveal a vertical displacement of $60-66 \mathrm{~m}$. It is also noticed that in Taitung area the depth of maximum oscillations is much shallower than that have been found in Hualien area $(400-800 \mathrm{~m})$, but similar to that reported in the South China Sea. The internal wave in Hualien area is likely generated at the southern flank of the Ryukyu Ridge (Pai et al. 2017) whereas the internal wave found in the present study may be related to the ridges in the Luzon Strait (Jan et al. 2007; Alford et al. 2011, 2015). For further information, readers may refer to a previous numerical study by Jan et al. (2008). Apart from scientific discussion, the data presented in this study and the phenomenon revealed can be of great value to marine engineers in further deployment of deep ocean water pipelines in Taitung area.

Acknowledgements The hydrography data were generously provided by the Water Resources Planning Institute, Water Resources Agency, Ministry of Economic Affairs, ROC (Ref. no. 10807009450). The authors would also like to express their gratitude to F. M. Chang and Taiwan Society of Deep Ocean Water Resources Application (TW-SOWA) for providing sampling facilities.

\section{REFERENCES}

Alford, M. H., J. A. MacKinnon, J. D. Nash, H. Simmons, A. Pickering, J. M. Klymak, R. Pinkel, O. Sun, L. Rainville, R. Musgrave, T. Beitzel, K.-H. Fu, and C.-W. Lu, 2011: Energy flux and dissipation in Luzon Strait: Two tales of two ridges. J. Phys. Oceanogr., 41, 22112222, doi: 10.1175/JPO-D-11-073.1. [Link]

Alford, M. H., T. Peacock, J. A. MacKinnon, J. D. Nash, M. C. Buijsman, L. R. Centurioni, S.-Y. Chao, M.-H. Chang, D. M. Farmer, O. B. Fringer, K.-H. Fu, P. C. Gallacher, H. C. Graber, K. R. Helfrich, S. M. Jachec, C. R. Jackson, J. M. Klymak, D. S. Ko, S. Jan, T. M. S. Johnston, S. Legg, I.-H. Lee, R.-C. Lien, M. J. Mercier, J. N. Moum, R. Musgrave, J.-H. Park, A. I.
Pickering, R. Pinkel, L. Rainville, S. R. Ramp, D. L. Rudnick, S. Sarkar, A. Scotti, H. L. Simmons, L. C. St Laurent, S. K. Venayagamoorthy, Y.-H. Wang, J. Wang, Y. J. Yang, T. Paluszkiewicz, and T.-Y. Tang, 2015: The formation and fate of internal waves in the South China Sea. Nature, 521, 65-69, doi: 10.1038/nature14399. [Link]

Jan, S., C.-S. Chern, J. Wang, and S.-Y. Chao, 2007: Generation of diurnal K1 internal tide in the Luzon Strait and its influence on surface tide in the South China Sea. J. Geophys. Res., 112, C06019, doi: 10.1029/2006JC004003. [Link]

Jan, S., R.-C. Lien, and C.-H. Ting, 2008: Numerical study of baroclinic tides in Luzon Strait. J. Oceanogr., 64, 789-802, doi: 10.1007/s10872-008-0066-5. [Link]

Lien, R.-C., F. Henyey, B. Ma, and Y. J. Yang, 2014: Largeamplitude internal solitary waves observed in the northern South China Sea: Properties and energetics. J. Phys. Oceanogr., 44, 1095-1115, doi: 10.1175/JPOD-13-088.1. [Link]

Pai, S.-C., S. Jan, K.-S. Chu, P.-Y. Huang, and M. M. Takahashi, 2015: Kuroshio or Oyashio - Sources of the 700 $m$ deep ocean water off Hualien coast, eastern Taiwan. Deep Ocean Water Research, 15, 107-116. Available at http://www.dowas.net/english/journals/15-3.html.

Pai, S.-C., C.-L. Wei, S. Lin, L.-S. Wen, and C.-M. Tseng, 2016: Observation of internal tide-induced nutrient upwelling in Hungtsai Trough, a submarine canyon in the northern South China Sea. Cont. Shelf Res., 120, 5967, doi: 10.1016/j.csr.2016.03.018. [Link]

Pai, S.-C., S. Jan, T.-Y. Ho, J.-Y. Liu, K.-S. Chu, W.-H. Lee, C.-Y. Wang, P.-Y. Huang, H.-Y. Hsu, and Y.-J. Yang, 2017: Using major nutrient concentrations to derive vertical movement of water masses in the coastal region of eastern Taiwan. J. Oceanogr., 73, 711-723, doi: 10.1007/s10872-017-0427-z. [Link]

Takahashi, M. M., P.-Y. Huang, and S.-C. Lee, 2012: Current status of deep ocean water (DOW) resource utilization in Taiwan. Deep Ocean Water Research, 13, 41-52. Available at http://www.dowas.net/paper/13-1. html. (in Japanese with English abstract) 